\title{
Structure and folding of a rare, natural kink turn in RNA with an $A \cdot A$ pair at the $2 b \cdot 2 n$ position
}

\author{
KERSTEN T. SCHROEDER, ${ }^{1,2}$ PETER DALDROP, ${ }^{1}$ SCOTT A. MCPHEE, and DAVID M.J. LILLEY ${ }^{3}$ \\ Cancer Research UK Nucleic Acid Structure Research Group, MSI/WTB Complex, The University of Dundee, Dundee DD1 5EH, \\ United Kingdom
}

\begin{abstract}
The kink turn (k-turn) is a frequently occurring motif, comprising a bulge followed by $G \bullet A$ and $A \bullet G$ pairs that introduces a sharp axial bend in duplex RNA. Natural k-turn sequences exhibit significant departures from the consensus, including the $A \cdot G$ pairs that form critical interactions stabilizing the core of the structure. Kt-23 found in the small ribosomal subunit differs from the consensus in many organisms, particularly in the second A•G pair distal to the bulge (2b•2n). Analysis of many Kt-23 sequences shows that the frequency of occurrence at the $2 n$ position (i.e., on the nonbulged strand, normally $G$ in standard k-turns) is $\mathrm{U}>\mathrm{C}>\mathrm{G}>\mathrm{A}$. Less than $1 \%$ of sequences have $\mathrm{A}$ at the $2 \mathrm{n}$ position, but one such example occurs in Thelohania solenopsae Kt-23. This sequence folds only weakly in the presence of $\mathrm{Mg}^{2+}$ ions but is induced to fold normally by the binding of L7Ae protein. Introduction of this sequence into the SAM-I riboswitch resulted in normal binding of SAM ligand, indicating that tertiary RNA contacts have resulted in k-turn folding. X-ray crystallography shows that the $T$. solenopsae Kt-23 adopts a standard k-turn geometry, making the key, conserved hydrogen bonds in the core and orienting the $1 \mathrm{n}$ (of the bulge-proximal A•G pair) and $2 \mathrm{~b}$ adenine nucleobases in position facing the opposing minor groove. The $2 \mathrm{~b}$ and $2 \mathrm{n}$ adenine nucleobases are not directly hydrogen bonded, but each makes hydrogen bonds to their opposing strands.
\end{abstract}

Keywords: RNA structure; k-turn; SAM-I riboswitch; X-ray crystallography; Thelohania solenopsae

\section{INTRODUCTION}

The kink turn (k-turn) is a widespread and important structural motif in duplex RNA that typically comprises a 3-nt bulge followed on its $3^{\prime}$ side by consecutive G•A and $A \bullet G$ pairs (Fig. 1A). k-turns generate a sharp kink into the axis of the helix and are very important in the architecture of large RNA species, where they can exert an important influence on the long-range structure and the formation of RNA-protein complexes. k-turns were first identified as a structural motif in both subunits of the ribosome (Klein et al. 2001), although they were independently observed as a repeated sequence in regulatory elements in RNA (Winkler et al. 2001). They are also present in the nucleolar RNA species that guide RNA modification (Hamma and Ferré-D’Amaré 2004; Moore et al. 2004; Szewczak et al. 2005; Youssef et al. 2007), U4

\footnotetext{
${ }^{1}$ These authors contributed equally to this work.

${ }^{2}$ Present address: LECOM-Bradenton, Bradenton, FL 34211, USA.

${ }^{3}$ Corresponding author.

E-mail d.m.j.lilley@dundee.ac.uk.

Article published online ahead of print. Article and publication date are at http://www.rnajournal.org/cgi/doi/10.1261/rna.032409.112.
}

snRNA (Vidovic et al. 2000; Wozniak et al. 2005), and in untranslated regions of mRNA (Mao et al. 1999; White et al. 2004), including within riboswitches (Montange and Batey 2006; Blouin and Lafontaine 2007; Heppell and Lafontaine 2008; Smith et al. 2009). k-turns are, consequently, involved in virtually every aspect of RNA function, including the translation and modification of RNA, spliceosome assembly, and the control of gene expression.

The tightly kinked geometry of the k-turn motif requires stabilization, in the absence of which the structure adopts a more gently bent structure, as expected for a normal 3-nt bulge. The folded k-turn can be stabilized in three different ways: first, by the addition of metal ions (Matsumura et al. 2003; Goody et al. 2004); second, protein binding can induce the formation of the kinked conformation (Turner et al. 2005), as exemplified by (though not limited to) the L7Ae family of proteins; and last, we have recently shown that tertiary interactions within a larger RNA species can stabilize the folded k-turn structure (Schroeder et al. 2011). It is likely that all these effects play a role in the ordered assembly of large RNA-protein complexes such as the ribosome, where the folding of different k-turns mediates long-range structural interactions and the structure becomes fixed by the 
A

Kt-7

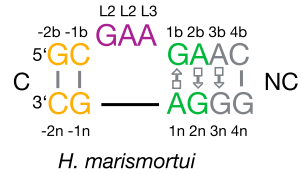

SAM-I rSW

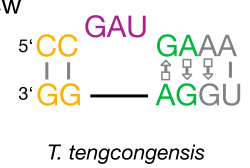

B

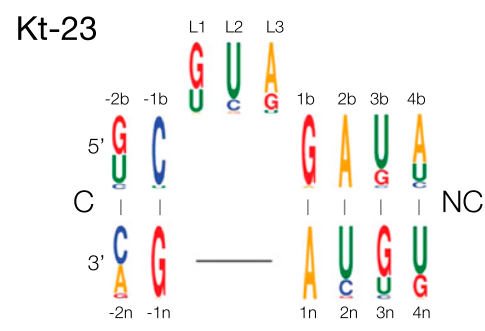

FIGURE 1. Sequences of $\mathrm{k}$-turns and consensus sequence of Kt23. $(A)$ Sequences of Kt-7, SAM-I, and Kt-23 k-turns. The k-turn sequence nomenclature (Liu and Lilley 2007) is indicated on the Kt-7 sequence; this scheme is used throughout this paper. (B) WebLogo (Crooks et al. 2004) analysis of Kt-23 sequences.

binding of different proteins. This would probably require that k-turns not be equally intrinsically stable and that proteins would bind with a range of affinities. We have shown that the near-consensus k-turn Kt-7 is induced to fold by the binding of Archeoglobus fulgidus L7Ae with an apparent affinity of $K_{\mathrm{d}}^{\text {app }}=10 \mathrm{pM}$ (Turner and Lilley 2008). However, other k-turns exhibit a significant departure from the consensus sequence and are likely to require greater stabilization of the kinked conformation. Examination of many k-turn sequences (Schroeder et al. 2010) reveals two kinds of departure from the standard sequence. We term simple k-turns as those where the ordering of the nucleotides within the sequence matches those of the standard k-turn such as Kt-7. However, within that framework, simple k-turns can exhibit sequence substitutions that differ from the consensus. In complex k-turns, the position of the nucleotides of the two critical G•A pairs in the structure does not map linearly onto the sequence. For example, the adenine in the $2 \mathrm{~b}$ position of Haloarcula marismortui Kt-15 actually arises from the nonbulged strand.

We have shown previously that the metal ion-induced folding of Kt-7 is completely intolerant to sequence changes in the two G•A pairs at the $1 \mathrm{~b} \bullet 1 \mathrm{n}$ and $2 \mathrm{n} \bullet 2 \mathrm{~b}$ positions (Goody et al. 2004). Yet, some natural k-turn sequences do depart from the consensus, including in these G•A pairs. $\mathrm{Kt}-23$ found in the small ribosomal subunit is commonly observed to have a nucleotide other than guanine at the $2 \mathrm{n}$ position (Fig. 1A). For example, in Thermus thermophilus, the $2 \mathrm{n}$ nucleotide is uridine, creating a non-Watson-Crick A.U pair at the $2 \mathrm{~b} \bullet 2 \mathrm{n}$ position (Wimberly et al. 2000). While making this change in Kt-7 generates a sequence that cannot be folded into k-turn geometry by addition of metal ions (Goody et al. 2004), the T. thermophilus Kt-23 sequence folds very well in the presence of $\mathrm{Mg}^{2+}$ or $\mathrm{Na}^{+}$ions (Schroeder and Lilley 2009). The sequence context was shown to be critical to the ion-induced stabilization of this Kt-23 sequence, with the nature of the $3 \mathrm{~b} \cdot 3 \mathrm{n}$ position especially important.

In the present study, we have used bioinformatics to investigate the range of Kt-23 sequences more broadly, finding that the majority of sequences lack guanine at the $2 \mathrm{n}$ position. A very minor subset of the sequences has adenine in the $2 \mathrm{n}$ position, creating a potential A•A pair at the $2 \mathrm{~b} \cdot 2 \mathrm{n}$ position. The potential equivalence of the structures of trans sugar-Hoogsteen $\mathrm{G} \bullet \mathrm{A}$ and $\mathrm{A} \bullet \mathrm{A}$ pairs is shown by the isostericity matrices of Leontis et al. (2002). While we have recently solved the crystal structure of a variant k-turn with such an A•A pair at that position stabilized by tertiary interactions in the SAM-I riboswitch, there are no structural data available for any natural, simple k-turn with this sequence. Using bioinformatics, we discovered that Thelohania solenopsae Kt-23 has just such a possible A•A pair at the $2 \mathrm{~b} \cdot 2 \mathrm{n}$ position. We have, therefore, studied this sequence, showing that it can adopt the k-turn conformation when stabilized either by L7Ae binding or by tertiary interactions in the SAM-I riboswitch. Using the latter, we have solved the crystal structure of this novel k-turn.

\section{RESULTS}

\section{Sequence variation in Kt-23}

$\mathrm{Kt}-23$ of the small ribosomal subunit rRNA exhibits a significant degree of sequence variation, particularly at the $2 \mathrm{~b} \cdot 2 \mathrm{n}$ position that is normally an $A \bullet G$ pair in standard k-turns such as Kt-7. Study of an alignment of 6325 sequences of $16 \mathrm{~S}$ and 18S rRNA (Cannone et al. 2002) revealed that the presence of an adenine at position $2 \mathrm{~b}$ is almost invariant ( $99.9 \%$ of all sequences), but the $2 \mathrm{n}$ position is more variable (for examples, see Supplemental Fig. S1). The 2n nucleotide is uridine in $96 \%$ of bacteria and $97 \%$ of archaeal sequences but in only $20 \%$ of eukaryotic sequences.

We have shown previously that the Kt-23 of T. thermophilus folds into a normal k-turn conformation in the presence of metal ions, despite the A $\bullet \mathrm{U}$ pair at the $2 \mathrm{~b} \bullet 2 \mathrm{n}$ position (Schroeder and Lilley 2009). We have generated a consensus sequence for Kt-23 from the alignment of $16 \mathrm{~S}$ and $18 \mathrm{~S}$ rRNA, represented using WebLogo 3 (Fig. 1B; Crooks et al. 2004). While this underlines that adenine at the $2 \mathrm{~b}$ position is strongly conserved, the frequency of occurrence of nucleotides at the $2 \mathrm{n}$ position is $\mathrm{U}>\mathrm{C}>\mathrm{G}>\mathrm{A}$. The occurrence of an $\mathrm{A}$ at this position is $\sim 1 \%$ in all domains of life. This raises the question of whether a potential k-turn having an A•A pair at 
the $2 \mathrm{~b} \cdot 2 \mathrm{n}$ position can fold into the kinked geometry, but there are no structural data available for any natural, simple k-turn with this sequence. We, therefore, sought an example of a Kt-23 sequence with an $\mathrm{A}$ at the $2 \mathrm{n}$ position to investigate structurally.

T. solenopsae is a microsporidial parasite of the fire ant, Solenopsis invicta (Knell et al. 1977). Its Kt-23 sequence is shown in Figure 1A. The sequence can be readily drawn as a simple k-turn, with a conventional G•A pair at the $1 \mathrm{~b} \bullet 1 \mathrm{n}$ position and an $\mathrm{A} \bullet \mathrm{A}$ pair at the $2 \mathrm{~b} \bullet 2 \mathrm{n}$ position. We have, therefore, explored the ability of this sequence to adopt the k-turn conformation.

\section{T. solenopsae $\mathrm{Kt}-23$ is weakly folded by $\mathrm{Mg}^{2+}$ ions}

Standard k-turns such as Kt-7 are induced to fold into their characteristic tightly kinked conformation as isolated duplexes by the addition of metal ions. This can be conveniently studied by fluorescence resonance energy transfer (FRET), using a short duplex RNA with the putative k-turnforming sequence at the center and fluorescein (donor) and Cy3 (acceptor) fluorophores attached at the two 5' termini. When the RNA adopts the kinked structure, the interfluorophore distance is reduced, with a corresponding increase in FRET efficiency $\left(E_{\mathrm{FRET}}\right)$. This was measured as a function of added $\mathrm{Mg}^{2+}$ ion concentration and plotted in Figure 2A. Addition of $\mathrm{Mg}^{2+}$ ions results in an increase in $E_{\mathrm{FRET}}$, and this is not observed in a variant where the $2^{\prime} \mathrm{O}$ atom has been deleted from the L1 position, thereby removing the possibility of forming the critical hydrogen bond to $\mathrm{N} 1$ of the conserved
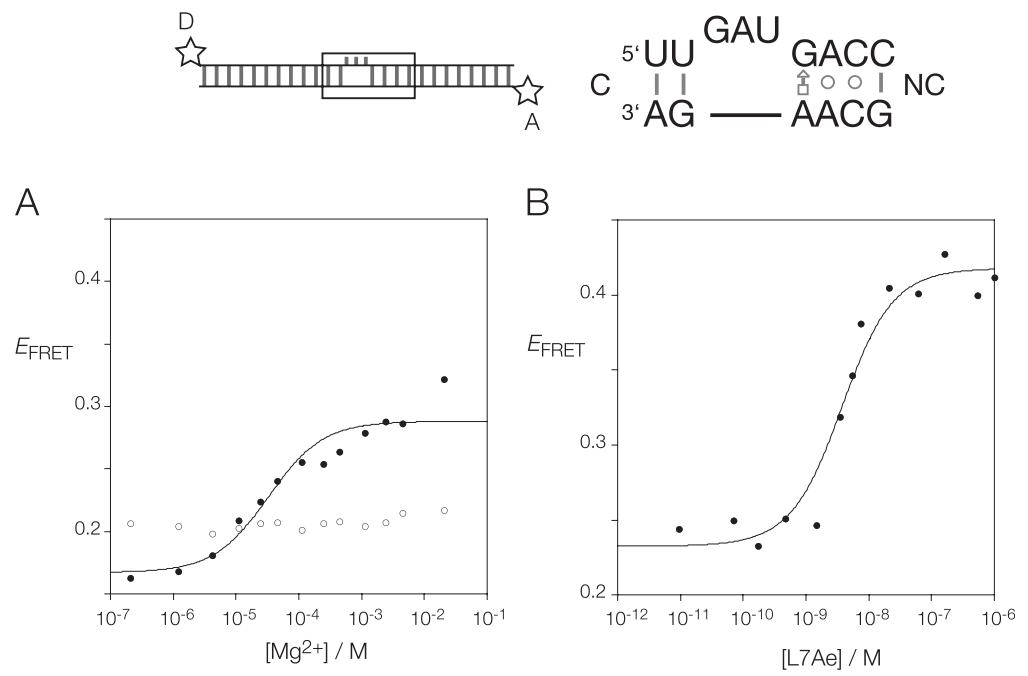

FIGURE 2. FRET analysis of the folding of T. solenopsae $\mathrm{Kt}-23$ induced by addition of $\mathrm{Mg}^{2+}$ ions and by L7Ae binding. The k-turn sequence was centrally located within a 25-bp RNA duplex terminally labeled with fluorescein (donor, D) and Cy3 (acceptor, A) fluorophores. FRET efficiency was measured in the steady-state. $(A) \mathrm{Mg}^{2+}$ ion-induced folding of the natural T. solenopsae Kt-23 (closed circles) and the L1 $2^{\prime} \mathrm{H}$ variant (open circles). The change in $E_{\mathrm{FRET}}$ was fitted using Equation (1). (B) L7Ae-induced folding of the natural T. solenopsae Kt-23. The change in $E_{\mathrm{FRET}}$ was fitted using Equation (2).
Aln nucleobase observed in the majority of k-turns of known structures (Liu and Lilley 2007). However, the extent of the change in FRET ( $\left.\Delta E_{\mathrm{FRET}}\right)$ is 0.12 , compared to $\geq 0.25$ for the majority of k-turn structures whose sequences approximate the consensus (Liu and Lilley 2007; Turner and Lilley 2008). The transition is relatively broad; fitting to a two-state model with a Hill coefficient constrained to $n=1$ gave a value of $\left[\mathrm{Mg}^{2+}\right]_{1 / 2}=36 \mu \mathrm{M}$, but this is not well defined by the data.

\section{Folding of $T$. solenopsae Kt-23 induced by the binding of L7Ae protein}

Protein binding provides a second way to induce the folding of some k-turn structures (Turner et al. 2005; Turner and Lilley 2008). In view of the rather weak folding of $T$. solenopsae $\mathrm{Kt}-23$ by the addition of $\mathrm{Mg}^{2+}$ ions, we examined the structure of the same fluorescein, Cy3-labeled Kt-23 RNA upon addition of A. fulgidus L7Ae protein, which induces the folding of standard k-turns such as Kt-7 and that of the box C/D RNA (Turner et al. 2005). We measured $E_{\text {FRET }}$ as a function of protein concentration, plotted in Figure 2B. A clear transition was observed, with an increase of FRET efficiency of $\Delta E_{\mathrm{FRET}}=0.23$, comparable to the range expected for full k-turn folding. Using a simple binding model, the apparent affinity of binding was $K_{\mathrm{d}}^{\mathrm{app}}=2.6 \mathrm{nM}$; this is several orders of magnitude lower than that measured for the same protein binding to Kt-7, where $K_{\mathrm{d}}{ }^{\text {app }}=10 \mathrm{pM}$ (Turner and Lilley 2008). Evidently, L7Ae induces the folding of $T$. solenopsae Kt-23 RNA but with a markedly reduced affinity. This is likely to result from the lower stability of the folded k-turn due to the $\mathrm{A} \bullet \mathrm{A}$ pair at the $2 \mathrm{~b} \bullet 2 \mathrm{n}$ position. If we assume that the lowering of affinity is solely due to the A•A pair, this indicates a destabilization of $13.9 \mathrm{~kJ} \mathrm{~mol}^{-1}$.

We have examined the effect of some atomic and sequence substitutions on the L7Ae-induced folding of $T$. solenopsae Kt-23 RNA. FRET efficiencies were measured as a function of L7Ae concentration and the data fitted as above (Supplemental Fig. S2). Values of $\Delta E_{\text {FRET }}$ and $K_{\mathrm{d}}$ app are presented in Table 1 . The largest effect arises from the L1 $2^{\prime} \mathrm{H}$ substitution, where the increase in FRET efficiency is only $\Delta E_{\mathrm{FRET}}=0.09$, and the apparent affinity is lowered by two orders of magnitude. These data have significant scatter, and the calculated affinity has a large error; nevertheless, a small degree of folding appears to have been induced by L7Ae protein, compared to none for the addition of $\mathrm{Mg}^{2+}$ ions. A second well-conserved hydrogen 
TABLE 1. Folding of $T$. solenopsae Kt-23 and sequence variants induced by L7Ae binding analyzed in solution by FRET

\begin{tabular}{lcc}
\hline RNA & $\Delta E_{\text {FRET }}$ & $\kappa_{\mathrm{d}}^{\text {app }} / \mathrm{nM}$ \\
\hline Kt-23 unmodified & $0.23 \pm 0.01$ & $2.7 \pm 0.8$ \\
L1 2'H & $0.09 \pm 0.02$ & $57 \pm 49$ \\
L3 2'H & $0.16 \pm 0.02$ & $74 \pm 33$ \\
C3bU & $0.13 \pm 0.02$ & $18 \pm 10$ \\
C3bG & $0.14 \pm 0.02$ & $28 \pm 20$ \\
\hline
\end{tabular}

The data are shown in Supplemental Figure S2.

bond is donated by the $\mathrm{L} 32^{\prime} \mathrm{OH}$ to the proS nonbridging $\mathrm{O}$ of the phosphate linking L1 and L2 in all k-turns (Liu and Lilley 2007). However, once again, deletion of this $\mathrm{O}$ atom does not completely prevent L7Ae-induced folding. The L3 $2^{\prime} \mathrm{H}$ substitution results in a reduced extent of folding $\left(\Delta E_{\mathrm{FRET}}=0.16\right)$ and an apparent affinity that is lowered by two orders of magnitude.

In our earlier study of the T. thermophilus Kt-23 k-turn, where there is an $\mathrm{A} \cdot \mathrm{U}$ pair at the $2 \mathrm{~b} \cdot 2 \mathrm{n}$ position, we found that the identity of the adjacent $3 \mathrm{~b} \bullet 3 \mathrm{n}$ pair was critical to the stability of the kinked conformation (Schroeder and Lilley 2009). In the T. solenopsae $\mathrm{Kt}-23$, the $3 \mathrm{~b} \cdot 3 \mathrm{n}$ pair is C.C. Replacement of this by either the potential WatsonCrick pair $\mathrm{G} \cdot \mathrm{C}(\mathrm{C} 3 \mathrm{bG})$ or a $\mathrm{U} \cdot \mathrm{C}$ pair $(\mathrm{C} 3 \mathrm{bU})$ did not prevent L7Ae-induced folding but significantly impaired the extent of folding and lowered the affinity of binding by an order of magnitude.

\section{The $T$. solenopsae Kt-23 is functional in the SAM riboswitch}

We have recently demonstrated a third process that can lead to stabilization of k-turns in the kinked conformation-the manipulation of the RNA by tertiary interactions within a larger RNA species (Schroeder et al. 2011). The Thermoanaerobacter tengcongensis SAM-I riboswitch contains a standard k-turn that kinks a long helix so that its terminus can make a loop-receptor interaction that is important for functional folding. Disruption of the k-turn leads to an RNA structure that no longer binds the S-adenosyl methionine (SAM) ligand that is straightforwardly analyzed by isothermal titration calorimetry (ITC). We showed that if we changed the standard $A \cdot G$ pair at the $2 \mathrm{~b} \bullet 2 \mathrm{n}$ position of the riboswitch $\mathrm{k}$-turn to $\mathrm{A} \bullet \mathrm{A}$, this prevented folding of the RNA as an isolated duplex, but that the same change within the riboswitch allowed SAM binding to occur unaffected, unlike changes at the $1 \mathrm{~b} \bullet 1 \mathrm{n}$ position. Clearly the tertiary interactions within the overall riboswitch structure stabilize the structure of the substituted k-turn, overcoming the effect that prevented folding of the isolated k-turn. We, therefore, engineered the $T$. solenopsae Kt-23 sequence into the corresponding position in the SAM-I riboswitch (Fig. 3A), and performed ITC using SAM as the ligand.
The ITC results are fully consistent with normal SAM binding to the hybrid riboswitch (Fig. 3B). SAM binds to the riboswitch in an exothermic reaction, and the data may be fitted to a binding model giving an affinity of $K_{\mathrm{d}}=0.49 \mu \mathrm{M}$ (Table 2), closely similar to $0.54 \mu \mathrm{M}$ measured for the riboswitch with the natural k-turn sequence (Montange et al. 2010; Schroeder et al. 2011). This is consistent with folding of the T. solenopsae Kt-23 sequence into normal k-turn geometry in the context of the riboswitch, indicating that the tertiary interactions facilitate folding of this k-turn.

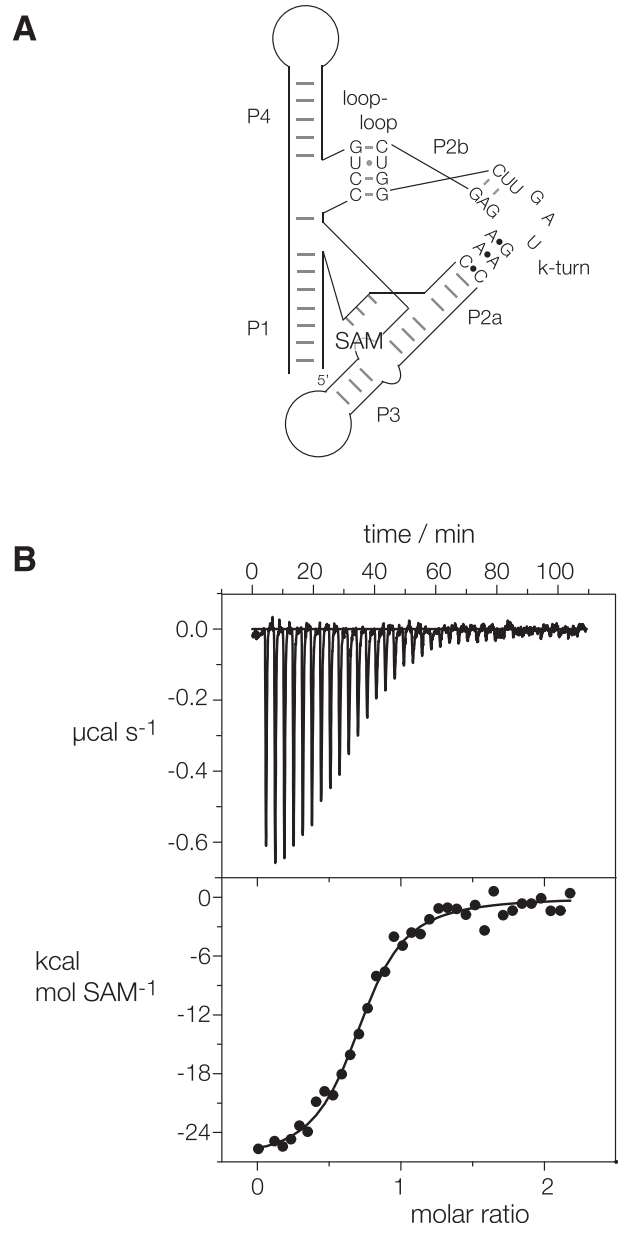

FIGURE 3. Isothermal titration calorimetric analysis of SAM binding to the SAM-I riboswitch in which the k-turn has been replaced by that of $T$. solenopsae Kt-23. A solution of SAM was titrated into a SAM-I riboswitch RNA solution, and the heat evolved was measured by ITC as the power required to maintain zero temperature difference with a reference cell. Integration over time gives the heat required to maintain thermal equilibrium between cells. (A) Scheme of SAM-I riboswitch with T. solenopsae Kt-23. (B) Calorimetric data. The upper panel shows the raw data for sequential injections of $8-\mu \mathrm{L}$ volumes (following an initial injection of $1 \mu \mathrm{L}$ ) of a $100 \mu \mathrm{M}$ solution of SAM into a $1.4 \mathrm{~mL} 10 \mu \mathrm{M}$ RNA solution in $50 \mathrm{mM}$ HEPES (pH 7.5), $100 \mathrm{mM} \mathrm{KCl,} 10 \mathrm{mM} \mathrm{MgCl} 2$. This represents the differential of the total heat (i.e., enthalpy $\Delta H^{\circ}$ under conditions of constant pressure) for each SAM concentration. The lower panel presents the integrated heat data fitted to a single-site binding model (Equation [3]). The thermodynamic parameters calculated are summarized in Table 2. 
TABLE 2. ITC-derived thermodynamic data for SAM binding to the SAM-I riboswitch

\begin{tabular}{lccrrc}
\hline k-turn & $n$ & $\Delta H^{\circ} / \mathrm{kJ} \mathrm{mol}^{-1}$ & $\Delta S^{\circ} / \mathrm{mol}^{-1} \mathrm{~K}^{-1}$ & $\Delta G^{\circ} / \mathrm{kJ} \mathrm{mol}^{-1}$ & $\mathrm{~K}_{\mathrm{d}} / \mu \mathrm{M}$ \\
\hline Natural & $0.8 \pm 0.1$ & $-73 \pm 5$ & $-120 \pm 22$ & $-36 \pm 1.2$ & $0.54 \pm 0.25$ \\
G2nA & $1.0 \pm 0.1$ & $-59 \pm 5$ & $-71 \pm 14$ & $-38 \pm 0.5$ & $0.31 \pm 0.06$ \\
TsKt23 & $1.0 \pm 0.3$ & $-86 \pm 30$ & $-160 \pm 50$ & $-37 \pm 1.1$ & $0.49 \pm 0.21$ \\
\hline
\end{tabular}

The natural k-turn, and variants with a single G2nA substitution (Schroeder et al. 2011) and with the $T$. solenopsae $\mathrm{Kt}-23$ replacing its normal k-turn. length, both having good geometry. As shown above, disruption of either leads to impairment of L7Ae-induced folding of the k-turn. k-turns in which the second nucleotide of the bulge (L2) is adenine frequently make an additional hydrogen bond between AL2 N6 and A2n O2'. This is also present in the T. solenopsae $\mathrm{Kt}-23$ structure, with a length of $2.8 \AA$ and good geometry.

\section{Crystal structure of the $T$. solenopsae Kt-23 in the SAM riboswitch}

The demonstration that the T. solenopsae Kt-23 sequence is functional in the SAM-I riboswitch and, therefore, probably folded into the k-turn conformation provided an opportunity to determine its structure by X-ray crystallography. We have shown previously that we can crystallize variants of the SAM-I riboswitch containing altered k-turn sequences and solve their structure straightforwardly by molecular replacement (Schroeder et al. 2011). Using the riboswitch as a kind of structural "cassette" in this way, we found that the Kt-23-containing RNA crystallized under closely similar conditions to those used for the natural riboswitch, with retention of the $\mathrm{P} 4_{3} 2_{1} 2$ space group and unit cell parameters (Montange et al. 2010). Diffraction data were collected and processed to a resolution of $2.95 \AA$ (Table 3), and initial phases were obtained by molecular replacement using the previously reported structure of the natural riboswitch, PDB code 2GIS (Montange and Batey 2006).

The overall structure of the modified SAM-I riboswitch was retained from the natural species (Supplemental Fig. S3), with an RMSD calculated over all P atoms of $0.63 \AA$ A. Both the riboswitch and its bound SAM ligand were well defined by the electron density. The k-turn is clearly visible within the structure (Fig. 4A), kinking the P2 helix so that it can dock its terminal loop into the receptor, a key interaction in the folding of the riboswitch into its functional form that creates the SAM binding site. The k-turn can be superimposed with the Kt-7 k-turn with an RMSD of $1.6 \AA$ (Fig. 4B). Although the superimposition was carried out using the phosphorus atoms, the A1n and A2b nucleobases are almost perfectly superimposed, showing that these key adenines are placed normally to make their interactions with the minor groove of the C helix. A composite omit map was calculated (Fig. 4C; Supplemental Figs. S4, S5) to exclude the possibility of model bias. This omit map clearly supports the obtained model with the great majority of the nucleotides very well resolved. Significantly for this study, the A2n and A2b nucleotides were well resolved (Fig. 4C).

The T. solenopsae Kt-23 structure has the near-universal standard hydrogen bonds involving 2'-hydroxyl groups (Fig. 4D; Liu and Lilley 2007). Both the GL1 O2' to A1n $\mathrm{N} 1$ and the UL3 O2' to PL1/PL2 proS O bonds are $2.7 \AA$ in
The core of the k-turn is shown in Figure 4C. As expected, the $1 \mathrm{~b} \bullet \mathrm{ln}$ base pair is a standard trans sugar-Hoogsteen pair, with two hydrogen bonds, from G1b N2 to A1n N7 and from A1n N6 to G1b N3, both $3.2 \AA$ in length. In the $2 \mathrm{~b} \cdot 2 \mathrm{n}$ position, we see that the A•A pair is oriented similarly to the A A pair in the SAM-I riboswitch G2nA k-turn structure (see Fig. 5A,B), with the nucleobase of the $\mathrm{A} 2 \mathrm{n}$ stacked between those of G1b and C3n. However, in contrast to the SAM-I G2nA riboswitch A•A pair, there is no direct hydrogen bonding between the two adenine bases; the position and orientation of the nucleobases are defined by the electron density unambiguously. The A•A pair of the SAM-I G2nA riboswitch is connected by a hydrogen bond from $\mathrm{A} 2 \mathrm{~b} \mathrm{~N} 6$ to A2n N3 (Fig. 5B), but the corresponding distance in the T. solenopsae Kt-23 structure is $5.0 \AA$. However, the two adenine bases are individually bonded into the k-turn

TABLE 3. Details of data collection and refinement statistics for the structure of the SAM-I riboswitch with the inserted Kt-23 from T. solenopsae

\begin{tabular}{|c|c|}
\hline & Details of data collection \\
\hline PDB code & $4 \mathrm{AOB}$ \\
\hline Space group & $\mathrm{P} 4{ }_{3} 2{ }_{1} 2$ \\
\hline \multirow[t]{4}{*}{ Unit cell dimensions/A } & $\mathrm{a}=61.30$ \\
\hline & $b=61.30$ \\
\hline & $\mathrm{c}=157.334$ \\
\hline & $\alpha=\beta=\gamma=90.00^{\circ}$ \\
\hline \multirow[t]{2}{*}{ Resolution range/Å } & $50-2.95$ \\
\hline & $(3.06-2.95)$ \\
\hline Observations & 64820 \\
\hline Unique observations & 6810 \\
\hline Completeness/\% & $98.5(89.5)$ \\
\hline$<\mathrm{l} / \sigma(\mathrm{I})>$ & $26.8(3.3)$ \\
\hline Multiplicity & $9.5(8.2)$ \\
\hline \multirow[t]{2}{*}{$R_{\text {merge }} \mathrm{a} \%$} & $11.1(46)$ \\
\hline & Refinement statistics \\
\hline Resolution range/ $/ \AA$ & 50-2.95 \\
\hline R-factor $\mathrm{b} / \%\left(\mathrm{R}_{\text {work }} / \mathrm{R}_{\text {free }}\right)$ & $18.9 / 23.9$ \\
\hline Number of atoms ${ }^{\mathrm{c}}$ & $2024 / 27 / 27 / 10$ \\
\hline Mean $B$-factor ${ }^{\mathrm{d}} / \AA^{2}$ & 74.7/62.7/101.8/36.4 \\
\hline RMS bond length deviation $/ \AA$ & 0.016 \\
\hline RMS bond angle deviation ${ }^{\circ}$ & 2.54 \\
\hline 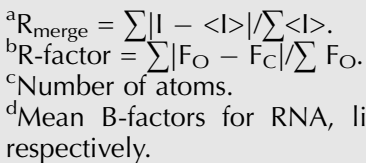 & , and water molecules, \\
\hline
\end{tabular}


A
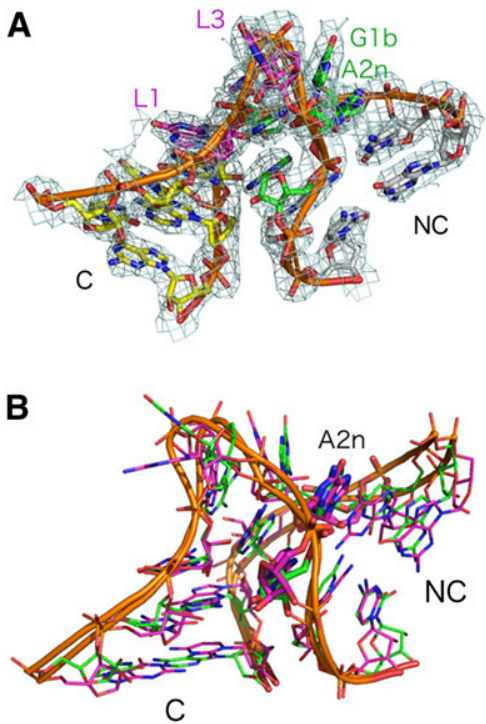

C

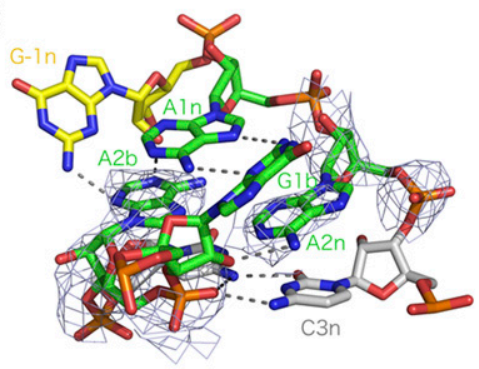

D

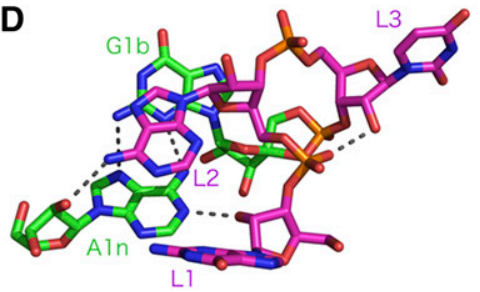

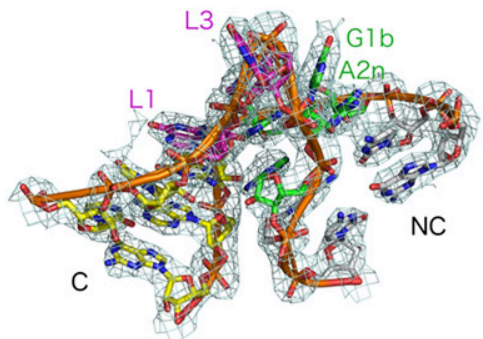

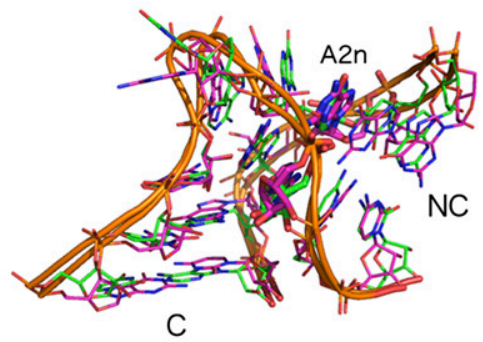

C
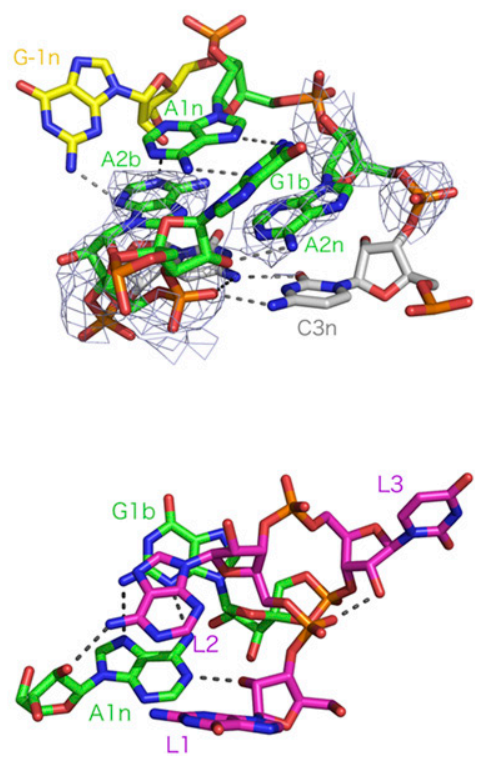

FIGURE 4. The crystal structure of the SAM-I riboswitch in which the k-turn has been replaced by that of T. solenopsae Kt-23. Parallel-eye stereo views are shown. $(A)$ The structure of the k-turn within the modified riboswitch. The $2 \mathbf{F}_{\text {obs }}-\mathbf{F}_{\mathrm{c}}$ electron density map is shown contoured at $1 \sigma$. The nucleotides are colored to match the schemes shown in Figure 1. (B) Superposition of Kt-23 (magenta) with the standard k-turn Kt-7 (green). The two k-turns were superimposed using their phosphorus atoms only. Note the close superimposition of Aln and A2b nucleobases (highlighted in stick form). (C) View from the nonbulged strand side of the core of the k-turn. The electron density shown on the A2b and A2n nucleotides is taken from the composite omit map. $(D)$ View down onto the loop to show the conserved hydrogen bonds.

structure (Fig. 4C). N6 of the A2n nucleobase hydrogen bonds with the $\mathrm{O}^{\prime}$ of $\mathrm{G} 1 \mathrm{~b}$ (length $3.1 \AA$ ). In addition, adenine $2 \mathrm{~b}$ makes two hydrogen bonds across the interface with the C helix; N3 accepts a bond from G-1n N2 (length $2.8 \AA$ ), and N1 accepts a bond from G-1n O2' (length $2.5 \AA$ ).

Moving to the $3 \mathrm{~b} \cdot 3 \mathrm{n}$ position, we have seen that the $\mathrm{C} 3 \mathrm{bU}$ and C3bG substitutions resulted in significant impairment of L7Ae-induced folding. We have previously observed that the nature of the $3 \mathrm{~b} \cdot 3 \mathrm{n}$ pair in T. thermophilus Kt-23 (with $\mathrm{U}$ at the $2 \mathrm{n}$ position) has a strong influence on the folding of that k-turn. A C.C pair occupies the $3 \mathrm{~b} \cdot 3 \mathrm{n}$ position in the $T$. solenopsae $\mathrm{Kt}-23$ structure. The cytosine nucleobases are coplanar, and well stacked into the helix. The C•C pair is linked by a single hydrogen bond between C3b N4 and C3n O2 (length 2.9 $\AA$ ). It would be disrupted by the C3bG substitution, but not by C3bU since this preserves the $\mathrm{C} 3 \mathrm{n} \mathrm{O} 2$, yet both changes destabilize k-turn folding in the presence of $\mathrm{Mg}^{2+}$ ions. However, C3b makes an additional hydrogen bond from $\mathrm{N} 4$ to the nonbridging pro $\mathrm{R} \mathrm{O}$ of the phosphate linking $1 \mathrm{n}$ and $2 \mathrm{n}$ that requires that $3 \mathrm{~b}$ be $\mathrm{C}$ and not $\mathrm{U}$. The $\mathrm{Cl}^{\prime}-$ $\mathrm{Cl}^{\prime}$ distance of the $\mathrm{C} \cdot \mathrm{C}$ pair (length $10.4 \AA$ ) is a close match to that of the $\mathrm{A} \bullet \mathrm{A}$ pair at the $2 \mathrm{~b} \bullet 2 \mathrm{n}$ position (length 10.6 $\AA$ ), which may provide some stabilization. The $4 \mathrm{~b} \bullet 4 \mathrm{n}$ position is a standard Watson-Crick C-G base pair.

\section{DISCUSSION}

$\mathrm{Kt}-23$ is a simple k-turn that frequently departs from the consensus sequence found for the motif. In particular, the majority of Kt-23 sequences do not have a guanine at the $2 \mathrm{n}$ position. Comparison of many Kt-23 sequences shows that the presence of adenine at the $2 \mathrm{n}$ position is extremely rare, and yet natural examples do exist. One such is the Kt-23 of T. solenopsae. We find that this sequence is only weakly folded by metal ions as an isolated duplex but that it is induced to fold either by the binding of L7Ae protein or by tertiary interactions within the SAM-I riboswitch. The latter allowed us to solve the X-ray crystal structure of this novel k-turn.

In most respects, the $T$. solenopsae Kt-23 structure is completely standard, both in global conformation and the formation of the normal hydrogen bonding patterns. The nucleobases of $\mathrm{A} 1 \mathrm{n}$ and $\mathrm{A} 2 \mathrm{~b}$ have their usual position and orientation seen in k-turns (Fig. 4B), enabling them to make A-minor interactions with the minor groove of the $\mathrm{C}$ helix. The only significant difference is the presence of the adenine at the $2 \mathrm{n}$ position (Fig. 5A). The orientation of the two purine nucleobases is closely similar to that in a normal 


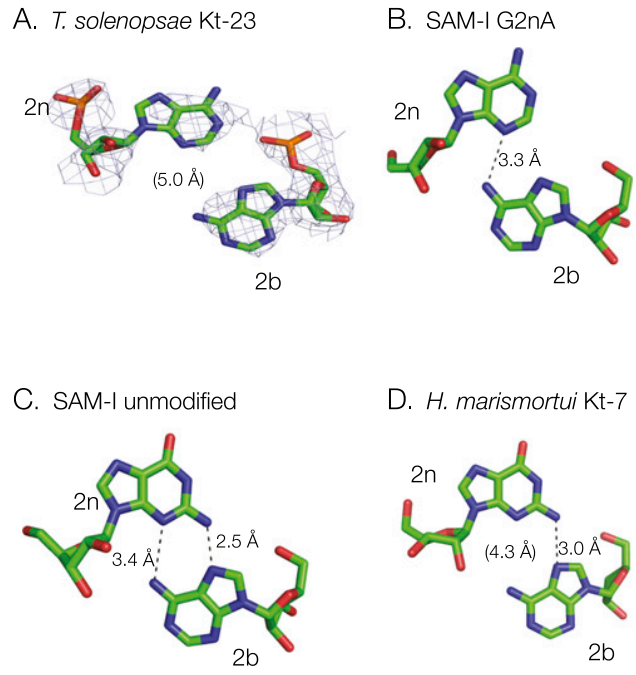

FIGURE 5. The structure of the $\mathrm{A} 2 \mathrm{~b}$ and $\mathrm{A} 2 \mathrm{n}$ nucleotides in the $T$. solenopsae $\mathrm{Kt}-23$ and comparison with $2 \mathrm{~b} \bullet 2 \mathrm{n}$ pairs observed in other k-turns. (A) T. solenopsae Kt-23. The electron density is taken from the composite omit map. (B) The SAM-I riboswitch G2nA k-turn (2YGH). (C) The SAM-I riboswitch k-turn (3GX5). (D) H. marismortui Kt-7 (1FFK).

k-turn (cf. that in the natural SAM-I riboswitch seen in Fig. 5C, for example), but there are no direct hydrogen bonds formed. By comparison, when we made the G2nA substitution in the SAM-I riboswitch, the resulting A॰A pair was linked by a single hydrogen bond donated from A2b N6 to $\mathrm{A} 2 \mathrm{n} \mathrm{N} 3$ of length $3.3 \AA$; the corresponding distance in the T. solenopsae Kt-23 structure is $5.0 \AA$. However, if A2n were replaced by $\mathrm{G}$ in the same position, the resulting exocyclic amine N2 would be able to hydrogen bond to A2n N7 with minimal movement. Interestingly, it seems that the hydrogen bond between A2b N6 to G2n N3 is not formed in many k-turns. For example, the corresponding N6-N3 distance in Kt-7 is $4.3 \AA$ (Fig. 5D), and the average distance observed in the simple k-turns Kt-7, box C/D, U4snRNA, Kt-38, Kt58 , and SAM-I riboswitch is $3.7 \pm 0.6 \AA$. The shortest of these, found in the U4 snRNA k-turn, is $3.1 \AA$, which is still a little longer than the optimal distance for hydrogen bonding. Perhaps the most extreme case of disruption of a $2 \mathrm{~b} \cdot 2 \mathrm{n}$ pair was found recently in a complex between a kturn and the bacterial L7Ae homolog YbxF, where A2b and G2n are neither base-paired nor even coplanar (Baird et al. 2012). In T. solenopsae $\mathrm{Kt}-23$, because of the separation of the nucleobases, the $\mathrm{Cl}^{\prime}$ to $\mathrm{Cl}^{\prime}$ distance at the $2 \mathrm{~b} \cdot 2 \mathrm{n}$ position is quite long at $10.6 \AA$, compared to $9.1 \AA$ for the corresponding distance at the $\mathrm{G} \bullet \mathrm{A}$ pair at the $\mathrm{lb} \bullet 1 \mathrm{n}$ position, and is close to that for a normal Watson-Crick base pair. Although the adenine nucleobases are relatively widely separated in the structure, each is linked to the backbone of the opposite strand by hydrogen bonding. Hydrogen bonds formed between $\mathrm{A} 2 \mathrm{~b}$ and the ribose and nucleobase of G-1n are a key part of the A-minor interactions with the C helix that probably contribute significantly to the stabilization of the k-turn conformation.

The structure of one other natural k-turn with an A•A pair at the $2 \mathrm{~b} \cdot 2 \mathrm{n}$ position is known, in the $16 \mathrm{~S}$ rRNA of T. thermophilus $\mathrm{Kt}-11$. However, this is a complex k-turn with a convoluted connectivity resulting in a different orientation of the nucleobases. The resulting cis HoogsteenWatson-Crick base pair is connected by two hydrogen bonds, from A2n N6 to A2b N7 (length $3.1 \AA$ ) and from A2b N6 to A2n N1 (length $2.9 \AA$ ). This stands in marked structural contrast to the A•A pair of the T. solenopsae Kt-23 $\mathrm{k}$-turn and all the simple k-turns.

The structure of the T. solenopsae Kt-23 k-turn shows how a rare variant of the consensus sequence can be tolerated within the structure, such that the global conformation is preserved with the retention of the majority of the key hydrogen bonding interactions. However, the poor folding induced by $\mathrm{Mg}^{2+}$ ions and the lower apparent affinity for L7Ae indicate a reduced stability of this sequence compared to standard k-turns such as Kt-7. Such differential stability between k-turns could be important in the biogenesis of large RNA-protein assemblies such as the ribosome, and the $2 \mathrm{n}$ position may have a major role in this discrimination.

\section{MATERIALS AND METHODS}

\section{Bioinformatic methods}

Sequences of rRNA from the small ribosomal subunit were obtained from the Comparative RNA Web Site (Cannone et al. 2002). The sequences of 6325 organisms were aligned by the k-turn nucleotides $-3 \mathrm{~b}$ through to $6 \mathrm{~b}$, and $6 \mathrm{n}$ to $-3 \mathrm{n}$. A consensus sequence for Kt-23 was drawn using WebLogo 3 (Crooks et al. 2004).

\section{RNA synthesis and construction of k-turn species}

Ribooligonucleotides were synthesized using $t$-BDMS phosphoramidite chemistry (Beaucage and Caruthers 1981), as described in Wilson et al. (2001). Fluorescein- and Cy3-conjugated oligonucleotides were attached at 5' termini as phosphoramidites during synthesis as required. Oligoribonucleotides were deprotected in $25 \%$ ethanol/ammonia solution at $55^{\circ} \mathrm{C}$ for $2 \mathrm{~h}$ and evaporated to dryness. Oligoribonucleotides were redissolved in $300 \mu \mathrm{L} 1 \mathrm{M}$ tetrabutylammonium fluoride (Aldrich) in tetrahydrofuran to remove $t$-BDMS protecting groups and agitated at $20^{\circ} \mathrm{C}$ for $16 \mathrm{~h}$ prior to desalting by G25 Sephadex (NAP columns, Pharmacia) and ethanol precipitation. All oligonucleotides were purified by gel electrophoresis in polyacrylamide and recovered from gel fragments by electroelution or diffusion in buffer, followed by ethanol precipitation. Fluorescently labeled RNA was subjected to further purification by reversed-phase HPLC on a C18 column (ACE10, Advanced Chromatography Technologies), using an acetonitrile gradient with an aqueous phase of $100 \mathrm{mM}$ triethylammonium acetate, $\mathrm{pH}$ 7.0. Duplex species were prepared by mixing equimolar quantities of the appropriate oligoribonucleotides and annealing them in $50 \mathrm{mM}$ Tris- $\mathrm{HCl}$ ( $\mathrm{pH} 7.5$ ), $25 \mathrm{mM} \mathrm{NaCl}$ by slow cooling from $90^{\circ} \mathrm{C}$ to $4^{\circ} \mathrm{C}$. They were purified by electrophoresis in $12 \%$ 
polyacrylamide under nondenaturing conditions and recovered by either electroelution or diffusion into buffer, followed by ethanol precipitation.

\section{RNA synthesis of the SAM-I riboswitch for ITC and crystallography}

The SAM-I riboswitch aptamer domain RNA was synthesized by in vitro transcription using T7 RNA polymerase and subsequently purified by polyacrylamide gel electrophoresis as described previously (Schroeder et al. 2011).

\section{Expression and purification of $A$. fulgidus L7Ae}

A pET28-b+ vector containing the gene for a hexahistidine-L7Ae fusion protein (supplied by Prof. A. Hüttenhoffer, Innsbruck) was transformed into Escherichia coli BL21-Gold (DE3) pLysS cells (Stratagene), and protein expression was induced by the addition of IPTG to $1 \mathrm{mM}$. The cells were shaken for $4 \mathrm{~h}$ at $37^{\circ} \mathrm{C}$ and harvested by centrifugation at $4000 \mathrm{rpm}$ for $30 \mathrm{~min}$ at $4^{\circ} \mathrm{C}$. The cells were immediately lysed in $20 \mathrm{mM}$ phosphate buffer ( $\mathrm{pH}$ 9.0), $0.5 \mathrm{M}$ $\mathrm{NaCl}, 2.5 \mathrm{mM}$ imidazole (buffer A), $5 \mathrm{mM} \mathrm{MgCl}_{2}$ containing 0.1 $\mathrm{mg} / \mathrm{mL}$ lysozyme (Sigma) and Complete protease cocktail (Roche). The suspension was heated at $85^{\circ} \mathrm{C}$ to denature endogenous protein, and this was removed by centrifugation at $10,000 \mathrm{rpm}$ for $30 \mathrm{~min}$ at $4^{\circ} \mathrm{C}$. L7Ae was purified from the cleared supernatant by application to a $\mathrm{Ni}^{2+}$-chelated HiTrap column (GE Healthcare) installed on an Äkta purifier HPLC (GE Healthcare) using $20 \mathrm{mM}$ phosphate buffer ( $\mathrm{pH} 9.0$ ), $500 \mathrm{mM} \mathrm{NaCl}$ (buffer A), and $20 \mathrm{mM}$ phosphate buffer ( $\mathrm{pH} 9.0$ ), $500 \mathrm{mM} \mathrm{NaCl}, 1 \mathrm{M}$ imidazole (buffer $\mathrm{B})$. After the protein was bound to the column, it was washed with three column volumes of $20 \mathrm{mM}$ phosphate buffer ( $\mathrm{pH} 9.0$ ), $2 \mathrm{M}$ $\mathrm{NaCl}$ (buffer $\mathrm{N}$ ). The bound protein was then dissociated from the column by a linear $0-500 \mathrm{mM}$ imidazole gradient, with the protein eluting at $\sim 200 \mathrm{mM}$ imidazole. The protein was dialyzed into 20 $\mathrm{mM}$ phosphate buffer ( $\mathrm{pH}$ 9.0) and applied to a HiTrap Heparin $\mathrm{HP}$ column (GE Healthcare) and eluted using a $\mathrm{NaCl}$ gradient; the protein eluted at $600 \mathrm{mM}$. This step was included to remove any RNA from the protein preparation. Pooled fractions were then dialyzed against $20 \mathrm{mM}$ HEPES-KOH (pH 7.4), $150 \mathrm{mM} \mathrm{KCl}, 1.5$ $\mathrm{mM} \mathrm{MgCl}_{2}$ (buffer C) containing $5 \% \mathrm{v} / \mathrm{v}$ glycerol before incubation with bovine thrombin (Sigma) for $16 \mathrm{~h}$ at $4^{\circ} \mathrm{C}$. After inactivation of the protease by heat treatment, L7Ae was concentrated and stored at $-20^{\circ} \mathrm{C}$ in buffer $\mathrm{C}$ containing $40 \% \mathrm{v} / \mathrm{v}$ glycerol. Protein concentration was calculated from its absorbance at $280 \mathrm{~nm}$, using $\varepsilon=6085 \mathrm{M}^{-1} \mathrm{~cm}^{-1}$, and the protein concentration was verified using the Bradford assay (Bradford 1976), with a kit purchased from BioRad employing bovine serum albumin as a standard. The purified protein was analyzed by electrophoresis in polyacrylamide in the presence of SDS, alongside a mixture of proteins $(2-212 \mathrm{kDa}$, New England BioLabs) to act as size standards.

\section{Study of $\mathrm{Mg}^{2+}$ - and L7Ae-induced folding by fluorescence resonance energy transfer}

Absorption spectra were measured in 90 mM Tris-borate ( $\mathrm{pH} 8.3$ ) in $2-\mu \mathrm{L}$ volumes using a Thermo Scientific NanoDrop 2000c spectrophotometer. Spectra were deconvoluted using a corresponding RNA species labeled only with Cy3 and fluorophore absorption ratios calculated using a MATLAB program. Fluores- cence spectra were recorded in $90 \mathrm{mM}$ Tris-borate $\left(\mathrm{pH} \mathrm{8.3)}\right.$ at $4^{\circ} \mathrm{C}$ using an SLM-Aminco 8100 fluorimeter. Spectra were corrected for lamp fluctuations and instrumental variations, and polarization artifacts were avoided by setting excitation and emission polarizers crossed at $54.7^{\circ}$. Values of FRET efficiency $\left(E_{\mathrm{FRET}}\right)$ were measured using the acceptor normalization method (Clegg 1992) implemented in MATLAB. $E_{\mathrm{FRET}}$ as a function of metal ion concentration was analyzed on the basis of a model in which the fraction of folded molecules corresponds to a simple two-state model for ion-induced folding, i.e.,

$$
E_{\mathrm{FRET}}=E_{0}+\Delta E_{\mathrm{FRET}} \cdot K_{A}[\mathrm{Mg}]^{n} /\left(1+K_{A}[\mathrm{Mg}]^{n}\right)
$$

where $E_{0}$ is the FRET efficiency of the RNA in the absence of added metal ions, $\Delta E_{\mathrm{FRET}}$ is the increase in FRET efficiency at saturating metal ion concentration, $[\mathrm{Mg}]$ is the prevailing $\mathrm{Mg}^{2+}$ ion concentration, $K_{A}$ is the apparent association constant for metal ion binding, and $n$ is a Hill coefficient. Data were fitted to this equation by nonlinear regression. The metal ion concentration at which the transition is half complete is given by $[\mathrm{Mg}]_{1 / 2}=$ $\left(1 / K_{A}\right)^{1 / n}$.

The same RNA oligonucleotides as used in the $\mathrm{Mg}^{2+}$-induced folding were used for the L7Ae binding experiments, and FRET was measured and analyzed using the same approach. L7Ae was added from a stock solution to a solution of $2 \mathrm{nM}$ solution of RNA. Apparent association constants $\left(K_{A}\right)$ were measured using a model of stoichiometric binding, i.e.,

$$
\begin{aligned}
& E_{\mathrm{FRET}}=E_{0}+\Delta E_{\mathrm{FRET}} \\
& \cdot \frac{\left(1+K_{A} P_{T}+K_{A} R_{T}\right)-\sqrt{\left(1+K_{A} P_{T}+K_{A} R_{T}\right)^{2}-4 R_{T} K_{A}^{2} P_{T}}}{2 R_{T} K_{A}}
\end{aligned}
$$

where $E_{O}$ is the initial FRET efficiency in the absence of added protein, $\Delta E_{F R E T}$ is the full range of the change in FRET efficiency, and $P_{T}$ and $R_{T}$ are the total concentration of L7Ae and RNA, respectively. The dissociation constant $K_{\mathrm{d}}=K_{A}{ }^{-1}$.

The sequences used in the FRET analyses were as follows (written $5^{\prime}$ to $3^{\prime}$ ):

\section{Kt-23 upper strand: Fluorescein-CCAGUCAGAUUUGAUGACCCCG GGAGAGG \\ Kt-23 lower strand: Cy3-CCUCUCCCGGGCAAGAAUCUGACUGG}

Single nucleotide substitutions were introduced as required.

\section{Isothermal titration calorimetry}

Microcalorimetric measurements of SAM binding to the SAM-I riboswitch and variants were performed by ITC as described by Montange et al. (2010). The sequence of the SAM-I riboswitch was

\section{5'-GGCUUAUCAAGAGAGGGCAAGAGACUGGCUUGAUGAC CCCCGGCAACCAAAAAUGGUGCCAAUUCCUGCAGAGGA AACGUUGAAAGAUGAGCCA-3'}

together with substitutions noted in the text. Calorimetric data were fitted to a single-site binding model, where possible, using MicroCal 
ORIGIN software. Individual heat changes $\Delta Q$ at constant pressure are given by

$$
\begin{aligned}
\Delta Q= & \mathrm{v} \cdot \Delta H \cdot[\mathrm{RNA}] \cdot\left\{\left(K_{\mathrm{a}} \cdot[\mathrm{SAM}]_{\mathrm{i}}^{\mathrm{n}} / 1+K_{\mathrm{a}} \cdot[\mathrm{SAM}]_{\mathrm{i}}^{\mathrm{n}}\right)\right. \\
& \left.-\left(K_{\mathrm{a}} \cdot[\mathrm{SAM}]_{\mathrm{i}-1}^{\mathrm{n}} / 1+K_{\mathrm{a}} \cdot[\mathrm{SAM}]_{\mathrm{i}-1}^{\mathrm{n}}\right)\right\}
\end{aligned}
$$

where $\Delta H$ is the change in enthalpy, $\mathrm{v}$ is the reaction volume, $K_{\mathrm{a}}$ is the association constant for SAM binding, and $[\mathrm{SAM}]_{\mathrm{i}}$ is the SAM concentration at the $i$ th injection.

\section{X-ray crystallography}

The SAM-I riboswitch was crystallized using the hanging drop method. The crystal from which the data set used to solve the structure was obtained was grown by mixing $1 \mu \mathrm{L}$ of $0.5 \mathrm{mM}$ RNA in $40 \mathrm{mM} \mathrm{Na}$-cacodylate ( $\mathrm{pH}$ 7.0) plus $5 \mathrm{mM}$ SAM with $1 \mu \mathrm{L}$ of mother liquor. The mother liquor contained $40 \mathrm{mM} \mathrm{Na}$-cacodylate ( $\mathrm{pH} 7.0$ ), $80 \mathrm{mM} \mathrm{KCl}, 30 \mathrm{mM} \mathrm{BaCl}_{2}, 12 \mathrm{mM}$ spermine-HCl, 8\% (v/v) MPD. The crystal was then cryo-protected with mother liquor containing $30 \%(\mathrm{v} / \mathrm{v})$ MPD and flash-frozen in liquid nitrogen.

Diffraction data were collected on beamline ID14-1 at the European Synchrotron Radiation Facility in Grenoble, France. The structure was solved by performing molecular replacement using MOLREP with the RNA plus SAM-ligand structure PDB entry 2GIS (Montange and Batey 2006) as a preliminary model. The model was subsequently refined using REFMAC5 (Vagin et al. 2004). Omit maps were calculated using PHENIX (Adams et al. 2010).

\section{SUPPLEMENTAL MATERIAL}

Supplemental material is available for this article.

\section{ACKNOWLEDGMENTS}

We thank Drs. James Procter and Lin Huang for discussion and the Cancer Research UK, the Wellcome Trust, and the Human Frontiers Science Program for financial support.

Received January 12, 2012; accepted March 28, 2012.

\section{REFERENCES}

Adams PD, Afonine PV, Bunkoczi G, Chen VB, Davis IW, Echols N, Headd JJ, Hung LW, Kapral GJ, Grosse-Kunstleve RW, et al. 2010. PHENIX: A comprehensive Python-based system for macromolecular structure solution. Acta Crystallogr D Biol Crystallogr 66: 213-221.

Baird NJ, Zhang J, Hamma T, Ferré-D'Amaré AR. 2012. YbxF and YlxQ are bacterial homologs of L7Ae, and bind K-turns but not K-loops. RNA 18: 759-770.

Beaucage SL, Caruthers MH. 1981. Deoxynucleoside phosphoramidites-a new class of key intermediates for deoxypolynucleotide synthesis. Tetrahedron Lett 22: 1859-1862.

Blouin S, Lafontaine DA. 2007. A loop-loop interaction and a K-turn motif located in the lysine aptamer domain are important for the riboswitch gene regulation control. RNA 13: 1256-1267.

Bradford MM. 1976. A rapid and sensitive method for the quantitation of microgram quantities of proteins utilizing the principle of protein dye binding. Anal Biochem 72: 248-254.

Cannone JJ, Subramanian S, Schnare MN, Collett JR, D'Souza LM, Du Y, Feng B, Lin N, Madabusi LV, Muller KM, et al. 2002. The comparative RNA web (CRW) site: An online database of comparative sequence and structure information for ribosomal, intron, and other RNAs. BMC Bioinformatics 3: 15. doi: 10.1186/ 1471-2105-3-15.

Clegg RM. 1992. Fluorescence resonance energy transfer and nucleic acids. Methods Enzymol 211: 353-388.

Crooks GE, Hon G, Chandonia JM, Brenner SE. 2004. WebLogo: A sequence logo generator. Genome Res 14: 1188-1190.

Goody TA, Melcher SE, Norman DG, Lilley DMJ. 2004. The kink-turn motif in RNA is dimorphic, and metal ion-dependent. RNA 10: 254-264.

Hamma T, Ferré-D’Amaré AR. 2004. Structure of protein L7Ae bound to a K-turn derived from an archaeal box H/ACA sRNA at $1.8 \AA$ resolution. Structure 12: 893-903.

Heppell B, Lafontaine DA. 2008. Folding of the SAM aptamer is determined by the formation of a K-turn-dependent pseudoknot. Biochemistry 47: 1490-1499.

Klein DJ, Schmeing TM, Moore PB, Steitz TA. 2001. The kink-turn: A new RNA secondary structure motif. EMBO J 20: 4214-4221.

Knell JD, Allen GE, Hazard EI. 1977. Light and electron microscope study of Thelohania solenopsae n. sp. (Microsporida: Protozoa) in the red imported fire ant, Solenopsis invicta. J Invertebr Pathol 29: 192-200.

Leontis NB, Stombaugh J, Westhof E. 2002. The non-Watson-Crick base pairs and their associated isostericity matrices. Nucleic Acids Res 30: 3497-3531.

Liu J, Lilley DMJ. 2007. The role of specific 2 '-hydroxyl groups in the stabilization of the folded conformation of kink-turn RNA. RNA 13: $200-210$.

Mao H, White SA, Williamson JR. 1999. A novel loop-loop recognition motif in the yeast ribosomal protein L30 autoregulatory RNA complex. Nat Struct Biol 6: 1139-1147.

Matsumura S, Ikawa Y, Inoue T. 2003. Biochemical characterization of the kink-turn RNA motif. Nucleic Acids Res 31: 5544-5551.

Montange RK, Batey RT. 2006. Structure of the $S$-adenosylmethionine riboswitch regulatory mRNA element. Nature 441: 1172-1175.

Montange RK, Mondragon E, van Tyne D, Garst AD, Ceres P, Batey RT. 2010. Discrimination between closely related cellular metabolites by the SAM-I riboswitch. J Mol Biol 396: 761-772.

Moore T, Zhang Y, Fenley MO, Li H. 2004. Molecular basis of box C/ D RNA-protein interactions; cocrystal structure of archaeal L7Ae and a box C/D RNA. Structure 12: 807-818.

Schroeder KT, Lilley DMJ. 2009. Ion-induced folding of a kink turn that departs from the conventional sequence. Nucleic Acids Res 37: 7281-7289.

Schroeder KT, McPhee SA, Ouellet J, Lilley DM. 2010. A structural database for k-turn motifs in RNA. RNA 16: 1463-1468.

Schroeder KT, Daldrop P, Lilley DMJ. 2011. RNA tertiary interactions in a riboswitch stabilize the structure of a kink turn. Structure 19: 1233-1240.

Smith KD, Lipchock SV, Ames TD, Wang J, Breaker RR, Strobel SA. 2009. Structural basis of ligand binding by a c-di-GMP riboswitch. Nat Struct Mol Biol 16: 1218-1223.

Szewczak LB, Gabrielsen JS, Degregorio SJ, Strobel SA, Steitz JA. 2005. Molecular basis for RNA kink-turn recognition by the h15.5K small RNP protein. RNA 11: 1407-1419.

Turner B, Lilley DM. 2008. The importance of G · A hydrogen bonding in the metal ion- and protein-induced folding of a kink turn RNA. J Mol Biol 381: 431-442.

Turner B, Melcher SE, Wilson TJ, Norman DG, Lilley DMJ. 2005. Induced fit of RNA on binding the L7Ae protein to the kink-turn motif. RNA 11: 1192-1200.

Vagin AA, Steiner RA, Lebedev AA, Potterton L, McNicholas S, Long F, Murshudov GN. 2004. REFMAC5 dictionary: Organization of prior chemical knowledge and guidelines for its use. Acta Crystallogr D Biol Crystallogr 60: 2184-2195.

Vidovic I, Nottrott S, Hartmuth K, Luhrmann R, Ficner R. 2000. Crystal structure of the spliceosomal $15.5 \mathrm{kD}$ protein bound to a U4 snRNA fragment. Mol Cell 6: 1331-1342. 
White SA, Hoeger M, Schweppe JJ, Shillingford A, Shipilov V, Zarutskie J. 2004. Internal loop mutations in the ribosomal protein L30 binding site of the yeast L30 RNA transcript. RNA 10: $369-377$.

Wilson TJ, Zhao Z-Y, Maxwell K, Kontogiannis L, Lilley DMJ. 2001. Importance of specific nucleotides in the folding of the natural form of the hairpin ribozyme. Biochemistry 40: 2291-2302.

Wimberly BT, Brodersen DE, Clemons WM Jr, Morgan-Warren RJ, Carter AP, Vonrhein C, Hartsch T, Ramakrishnan V. 2000. Structure of the $30 \mathrm{~S}$ ribosomal subunit. Nature 407: 327-339.
Winkler WC, Grundy FJ, Murphy BA, Henkin TM. 2001. The GA motif: An RNA element common to bacterial antitermination systems, rRNA, and eukaryotic RNAs. RNA 7: 1165-1172.

Wozniak AK, Nottrott S, Kuhn-Holsken E, Schroder GF, Grubmuller H, Luhrmann R, Seidel CA, Oesterhelt F. 2005. Detecting protein-induced folding of the U4 snRNA kink-turn by singlemolecule multiparameter FRET measurements. RNA 11: 15451554.

Youssef OA, Terns RM, Terns MP. 2007. Dynamic interactions within sub-complexes of the H/ACA pseudouridylation guide RNP. Nucleic Acids Res 35: 6196-6206. 

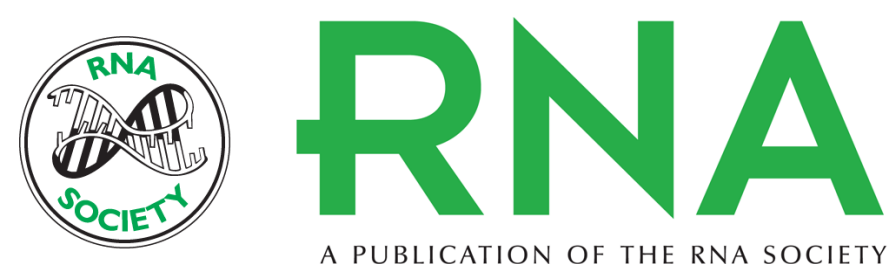

A PUBLICATION OF THE RNA SOCIETY

\section{Structure and folding of a rare, natural kink turn in RNA with an A•A pair at the $2 b \cdot 2 n$ position}

Kersten T. Schroeder, Peter Daldrop, Scott A. McPhee, et al.

RNA 2012 18: 1257-1266 originally published online April 26, 2012

Access the most recent version at doi:10.1261/rna.032409.112

Supplemental http://rnajournal.cshlp.org/content/suppl/2012/04/03/rna.032409.112.DC1
Material

References This article cites 35 articles, 12 of which can be accessed free at: http://rnajournal.cshlp.org/content/18/6/1257. full.html\#ref-list-1

License

Email Alerting Receive free email alerts when new articles cite this article - sign up in the box at the Service top right corner of the article or click here.

To subscribe to RNA go to:

http://rnajournal.cshlp.org/subscriptions 